\title{
Study on Synergistic Development of Ice and Snow Industry Between Heilongjiang Province and Russia
}

\author{
Shouwen Wang ${ }^{1 *}$
}

\author{
${ }^{1}$ Heihe University, Heihe, Heilongjiang, China \\ *Corresponding author. Email: 24208379@qq.com
}

\begin{abstract}
The continuous development of economy and society and the strengthening of international trade cooperation lead to more economic, political and cultural exchanges between China and its neighbors. As an important neighbor of China, Russia has strong edges in geographical location, politics and economy, and has a large space for cooperation in international and regional affairs. In particular, the proposal and development of "One Belt And One Road" strategy made Russia, which has a unique geographical position, occupy an important position on the northern Silk Road. Strengthening the economic cooperation with Russia is of great positive significance to the development of the new economic and trade pattern and the in-depth economic development of both Russia and China. The synergistic development of ice and snow industry between Heilongjiang Province and Russia can be analyzed and studied from the perspective of cultural exchange in this paper. Based on the different national conditions and development strategies of each country, the paper aims to understand the differences in the development of ice and snow industry between the two countries, improve the regional development cooperation mechanism, give play to the resources and other advantages of their respective regions, and promote the synergistic development of ice and snow industry.
\end{abstract}

Keywords: Heilongjiang, Russia, Ice and snow industry, Synergistic development, Research.

\section{INTRODUCTION}

Heilongjiang Province and the Russian Far East are located in an important position of Wogong Longjiang Silk Road Economic Belt. "ChinaMongolia-Russia Economic Corridor - Longjiang Silk Road Economic Belt" covers a relatively wide area, mainly belonging to the temperate zone, subfrigid zone and other climatic range, which enjoys the characteristics of large-scale monsoon climate. The winter is long, the temperature is low, the snowfall is abundant, and the ice and snow resources are abundant, thus the potential to develop the ice and snow industry. China's ice and snow industry is still in its infancy, with ice and snow recreation and ice

*Fund: This paper is the research result of the following projects: "Research on the Synergetic Development of Ice and Snow Industry between Heilongjiang Province, China and Amur Region, Russia", a key project of Heilongjiang Province's 13th Five-Year Plan for Education and Science in 2020 (Project number: GJB1320214); "Research on the Collaborative Development of Ice and Snow Industry and Culture in Heilongjiang Province of China and Amur Region of Russia", Art and Science Planning Project of Heilongjiang Province in 2020 (Proiect number: 2020D029) and snow sports taking the leading position. On the whole, China's ice and snow industry is mainly developed in Northeast China, including Northwest China and North China. The development of ice and snow industry in Heilongjiang is relatively prominent, and the competition of ice and snow market among different regions and sectors is becoming fierce [1]. In recent years, China's ice and snow industry has also entered a peak period of development. The development mode of industrial integration has been continuously intensified, and an industrial chain has been gradually formed. At the same time, China's support for the development of the ice and snow industry is also increasing, and it has been gradually getting rid of the original development models such as imitation and low-end processing, and gradually moving towards branding [2]. At the same time, the market of ice and snow products is also expanding, and the exchanges with the ice and snow industry in the Russian Far East are increasingly closer. The research on the synergistic development of Heilongjiang and Russia's ice and 
snow industry is of practical significance to the overall economic development of China and Russia.

\section{ANALYSIS ON THE DEVELOPMENT STATUS OF ICE AND SNOW INDUSTRY IN RUSSIA}

Russia stretches across the Eurasian continent, covering a vast area, mainly located in the North Temperate Zone. Therefore, the local area has a long winter with relatively rich snowfall and abundant ice and snow resources. At the same time, the North Caucasus Mountains have unique natural resources advantages, which make it have similar conditions and cultural basis to the European skiing environment [3]. According to statistics, Russia has more than 300 ski venues, and there are more than 40 ski resorts in the vicinity of Moscow alone. Russia has a total population of 140 million, but its total number of skiers accounts for $3 \%$, ranking in the upper middle of the world [4]. As early as 2014, Russia successfully hosted the Sochi Winter Olympic Games, which also successfully proved to the world its international status as an ice and snow country and a sports power. In recent years, Russia has been constantly improving its own infrastructure, sports venues, etc., and actively provides more superior and perfect training conditions for athletes, so as to better equip athletes with edges in skiing, skating and other competition events. The results of the Winter Olympics show that Russia also has great advantages and progress in the competition at each Winter Olympics. In the 15 Winter Olympics, the Soviet Union won 11 gold, 9 silver and 9 bronze medals, accounting for the first place in the overall medal list. Also, in the 17th Winter Olympics, Russia participated for the first time as an independent organization. It won 11 gold medals, 8 silver medals and 4 bronze medals, which was also the first overall medal winner. In its own Winter Olympics in Sochi, Russia did well, continuing to lead the country in overall medals, including 13 gold medals - its best finish in history and the first country to win more than 30 medals in a Winter Olympics. Russia's status as a sports powerhouse has also been confirmed.

\section{SPATIAL ANALYSIS OF SYNERGISTIC DEVELOPMENT OF ICE AND SNOW INDUSTRY BETWEEN HEILONGJIANG AND RUSSIA}

\subsection{Analysis of the International Situation}

The regional economy of Northeast Asia area is integrated gradually. In view of the implementation of One Belt And One Road development strategy, Russia has also proposed a trans-Eurasian development belt. The economic exchanges between China and Russia are becoming more and more significant, and there are more and more opportunities for industrial cooperation to effectively realize resource complementarity. Tourism involves a lot of content and needs to be integrated with other industries. Tourism has regional characteristics and is also a worldwide industry. China and Russia are both countries in Northeast Asia and have rich ice and snow resources due to the influence of climatic conditions [5]. Against the background of the rapid development of international ice and snow tourism, strengthening the cooperation between China and Russia in the ice and snow industry is both an inherent need and an important development trend of the tourism industry. It can effectively strengthen the political, economic, cultural and scientific and technological exchanges between China and Russia, and also promote the development of One Belt And One Road strategy.

\subsection{Political Advantage}

China and Russia are neighbors. Both in history and at present, the two sides have had more exchanges and frequent political and economic interactions, which has created a good environment for bilateral cooperation. In particular, the northeast region of China is geographically close to the Far East region of Russia, and it is also the focus of the development of China and Russia. More funds have been invested in both regions, which have played a greater role in promoting the development of Heilongjiang Province and the Far East region of Russia. Under the guidance of the new strategic thinking, China's ice and snow industry has developed rapidly following the successful bid for the 2022 Beijing Winter Olympic Games. Heilongjiang Province is an important region for the development of ice and snow industry in China, and it is necessary to strengthen the development of ice and snow industry with the help of new development policies. At the same time, Russia successfully hosted the Sochi Winter Olympics in 2014, and its snow and ice tourism is also growing. The Russian Far East is rich in ice and snow resources, and there is still a large space for the development of ice and snow tourism industry. Strengthening the cooperation between Heilongjiang Province and Russia in the ice and snow 
industry can effectively broaden the field of Heilongjiang's ice and snow industry development, and also effectively change the development pattern of Russia's ice and snow industry.

\subsection{Resource Superiority}

As for the development of tourism, both Russia and China have abundant tourism resources. However, for the far east region, which is located in the One Belt And One Road development strategy and the China-Mongolia-Russia Economic Corridor - Longjiang Silk Road Economic Belt, there are relatively few people here, so the tourism industry lags behind relatively. However, the region is rich in tourism resources, such as lakes, forests, glaciers, etc. Apart from natural resources, there are also many national cultural resources, which also create good conditions for the development of the ice and snow industry [6]. Similarly, Heilongjiang Province in China also has rich resources, including large wetlands, forests and grasslands, as well as some cultures and customs with national characteristics. Therefore, it is of great value to effectively combine the resources of the Far East and Heilongjiang province to establish a unique ice and snow tourism resort.

\subsection{Economic Advantages}

In recent years, with the continuous strengthening of China's foreign trade, China plays a more and more important role in the development of the world economy. Meanwhile, Russia is also a major economic power in the world. Strengthening cooperation and exchanges between the two countries and handling the development of relations in the border areas have also laid a good foundation for the development of tourism. China, the world's second largest economy, is the world's ultimate outbound investor. In recent years, with the continuous improvement of infrastructure and the strengthening of development efforts, the cooperation and exchanges in the ice and snow industry can also achieve the full docking of capital and resources, adapt to the docking of market supply and demand, and effectively solve the trade deficit in the development of trade between China and Russia.

\subsection{Industrial Strength}

As a country of ice and snow and ice sports, Russia has rich experience in hosting the Winter Olympics. China's enhanced cooperation with Russia in the ice and snow industry will also provide rich experience for China to host the 2022 Beijing Winter Olympic Games. At the same time, in view of the huge differences in cultural development between China and Russia, the two sides need to strengthen cultural exchanges in cooperation to achieve complementarity and lay a foundation for the development of the ice and snow industry, so as to promote healthy competition and sustainable development of bilateral cooperation.

\section{SYNERGISTIC DEVELOPMENT OF ICE AND SNOW INDUSTRY BETWEEN HEILONGJIANG AND RUSSIA}

\subsection{Strengthening Trade Cooperation Between China and Russia}

China and Russia are friendly neighbors and important trading partners. At present, the international ice and snow industry has developed to a large extent, and China and Russia are also actively seeking cooperation in the development of the ice and snow industry. The differences in the development of the ice and snow industry between the two countries can be understood from the perspectives of different national conditions and development strategies of different countries [7]. For example, the people of Heilongjiang Province and the people of Russia have different demands for the development of ice and snow industry and tourism products, and the two sides can realize the complementarity of resources and products. In addition, the development of tourism industry needs the support of other industries and the continuous improvement of infrastructure and so on. Russia's light industry development is relatively slow, with a huge resource advantage. Russia can make up for China's deficiency in the production of ski substrate. After deep processing in China, it will be sold to other countries to achieve trade cooperation.

\subsection{Enhancing Service Cooperation}

The development of ice and snow industry involves many contents, mainly relying on ice and snow resources. The in-depth development and utilization of ice and snow resources, and the integrated development of catering, accommodation, transportation and other industries, will ultimately promote the integrated development of the industry. Skiing tourism and ice and snow tourism are important contents of the development of ice and snow industry, as well as important service industries, which need to consider the experience and 
satisfaction of users. Therefore, industrial cooperation and development need to attach importance to integrating services into ice and snow products to realize value-added development of the tourism industry. The habits, cultural backgrounds and living characteristics of people in China and Russia should be taken into consideration to design ice and snow tourism products suitable for people's needs.

\subsection{Taking Full Advantage of Resources}

Heilongjiang Province is similar to the Russian Far East in terms of geographical location and climatic conditions, but there are some differences in mountains, rivers and lakes. Therefore, the snow and ice resources of the two places are also different. Russia is relatively rich in natural resources, including Lake Baikal and Caucasus Mountain, which is suitable for snow and ice cross-country, ice lake recreation, etc. It is also an international ski resort [8]. China's Harbin Ice and Snow World, the International Ice and Snow Festival and other festivals are also well known. Differences in ice and snow products should also be taken into account to provide people with more diversified travel products.

\subsection{Strengthening Market Cooperation}

For Russia and Heilongjiang Province, regardless of political factors, they mainly seek for economic cooperation, exchange and development, and ultimately drive social development along the Mongolia-Russia Economic Corridor. The region is vast, the culture is diverse, and the market demand is also very different, so the final products will also be different. From the perspective of regional development, in order to realize the integration of market, economy and service and promote the longterm economic development, it is still necessary to take the market as the basis, understand the market demand and market changes, and promote the longterm development of the ice and snow industry.

\subsection{Enhancing Cultural Cooperation}

The current development and competition in the world is still a cultural competition. From the actual development of ice and snow industry, its cultural deposits and deep connotation are the important factors to promote its long-term development. Therefore, cultural elements should be gradually infiltrated into the development of the ice and snow industry in the process of development to eventually form diversified ice and snow tourism products and drive the long-term development of the ice and snow industry.

\section{CONCLUSION}

To sum up, the proposal of One Belt And One Road has strengthened the economic exchanges and cooperation between China and Russia and other countries and regions. Heilongjiang Province, with its special geographical location, is rich in ice and snow resources. In the future development, it is necessary to strengthen exchanges and cooperation with Russia and other regions, improve the regional development cooperation mechanism, strengthen economic and cultural exchanges and cooperation, and give full play to the resources and other advantages of their respective regions to promote the coordinated development of the ice and snow industry.

\section{AUTHORS’ CONTRIBUTIONS}

This paper is independently completed by Shouwen Wang.

\section{REFERENCES}

[1] Sui Jiayi. Research on the Development Strategy of Ski Tourism Industry in Heilongjiang Province from the Perspective of "Industrial Convergence" [D]. Harbin Institute of Physical Education, 2020. (in Chinese)

[2] Zhou Dongmei. Research on Tax policy for promoting the development of ice and snow tourism industry in Heilongjiang Province [D]. Harbin University of Commerce, 2020. (in Chinese)

[3] Liu Fengzhi. Research on Supporting Policies for the Development of Ice and Snow Industry in Heilongjiang Province [D]. Harbin University of Commerce, 2020. (in Chinese)

[4] Wang Yuting, Song Jihua. Research on the integration and development of the ecological agriculture industrial chain in Heilongjiang and the Russian Far East [J]. Market Modernization, 2020(08): 133-134. (in Chinese)

[5] Liu Xiaoyu, Yang Liu. Research on Agricultural Products Trade between Heilongjiang Province and Russia $[\mathrm{J}]$. Market Modernization, 2020(07): 67-68. (in Chinese)

[6] Liang Shuyu. Analysis of the impact of SinoRussian Heilongjiang Bridge on bilateral trade 
[D]. Harbin University of Commerce, 2020. (in Chinese)

[7] Liu Chunfu, Xu Yanyan. Research on the efficiency of Heilongjiang Province's trade with Russia under the background of "One Belt One Road" [J]. Enterprise Economy, 2019, 38(11): 48-54. (in Chinese)

[8] Huang Lei, Lin Xianpeng. Research on the development potential of my country's ice and snow industry from the current situation of the skating industry $[\mathrm{J}]$. Hubei Social Sciences, 2019(10): 78-83. (in Chinese)

[9] Zhang Guihai. The concept of deepening SinoRussian ice and snow industry cooperation under the background of "One Belt One Road" [J]. Siberian Studies, 2017, 44(04): 34-38. (in Chinese) 